\title{
冗長関節リーチング問題の不良設定性を自然解消する 重力補償つき制御法と書字ロボットへの応用
}

\author{
有本卓* 橋 口宏 衛* \\ A Control Scheme with Gravity Compensation Naturally Resolving the Ill-posedness \\ of Redundant Multi-joint Reaching and Its Application to Handwriting Robots
}

Suguru ARImoto* and Hiroe HaShiguchi*

\begin{abstract}
In order to enhance dexterity in execution of robot tasks a surplus number of DOFs (Degrees of Freedom) is necessary for design of robotic mechanisms. In case of such redundant robots, it is said that a problem of inverse kinematics becomes ill-posed and therefore an extra performance index is indispensable to determine uniquely the inverse mapping from task space to joint space. This paper treats a problem of reaching tasks under the effect of gravity by a redundant robot arm or hand and shows that such ill-posedness of DOF redundancy can be resolved in a natural way by using a simpler task-space feedback with adequate dampings at joints and gravity compensation and without introducing any extra performance index. An application of the proposed method to control of hand-writing robots is also discussed.
\end{abstract}

Key Words: redundancy resolution, multi-joint reaching, ill-posed inverse kinematics, gravity compensation, handwriting robots

\section{1.はじめに}

人間らしい運動を行ない, 器用に作業するロボットの実現 を目指し，人間の腕や手に似せてロボットアームを造ると， それは圥長自由度系になる。圥長自由度系に対しては, 作業 空間から関節空間への逆運動学が不良設定になり，作業を実 現する制御系を設計するためには，人為的な動作指標を導 入し，それを最小化して不良設定性を解消せねばならない とされてきた。しかし，人間は，複雑な計算を行なうこと なく, 自由自在に運動を生成し, 器用な作業を行なう。この 謎は Bernstein の問題と呼ばれ ${ }^{1)}$, 心理学や運動生理学では さまざまな仮説が提案されてきたが, 根本的な解決には至っ ていない2). しかし, ごく最近, 逆運動学を解かなくても, 作業座標フィードバックによって圥長自由度系に対する逆運 動学の不良設定性が自然に解消できることが, 最も単純な 水平面下に運動を限定した多関節りーチング問題について, 初めて示された ${ }^{3)}$. また，圥長自由度をもつ書字ロボットに ついても，重力項が直接補償できれば，平面リーチング問題 と同様に，ダンピング成形つき作業座標フィードバックが有 効であることが, 理論的 ${ }^{4)}$, かつ実験的 ${ }^{5), 6)} に も も$ 示された.

* 立命館大学理工学部ロボテイクス学科 草津市野路東 1-1-1

* Department of Robotics, Ritsumeikan University, Kusatsu (Received February 3, 2005)

(Revised August 1, 2005)
本論文では，垂直平面下で回転する三つの関節（これらの 関節軸は $x y$ 平面にある) と $z$ 軸まわりに回転する関節の 四関節リーチング運動について, 逆運動学や逆動力学を解か ないで制御する自然な方法を提案し, その有効性を理論解 析するとともに，シミュレーション結果を示す．また，提案 の方法を書字ロボットの制御の応用し，その有効性をシミュ レーションで明らかにする.

\section{2. 重力下における冗長多関節リーチングとその ダイナミクス}

Fig. 1 の模式図に示すような書字ロボットについて, ペン 先を $x y$ 平面の上のほうにある初期位置 $\boldsymbol{x}^{0}\left(=\left(x^{0}, y^{0}, z^{0}\right)\right)$ から $x y$ 平面上の目標点 $x_{d}\left(=\left(x_{d}, y_{d}, z_{d}=0\right)\right)$ にもって いく制御法を考える。ここに，当然であるが， $z^{0}>0$ であ $\eta$, 制御開始から終了までペン先位置 $\boldsymbol{x}(=(x, y, z))$ の $z$ は負になってはならないし, ペンを含めたロボットのリン

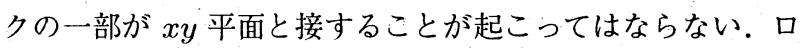
ボットの関節座標を $q=\left(q_{1}, q_{2}, q_{3}, q_{4}\right)^{\mathrm{T}}$ にとると, Fig. 1 は形式的には Fig. 2 のように定式化できよう。このとき， ペン先の位置が $x y$ 平面より上にある限り，ロボットの運動 はラグランジュの運動方程式

$$
H(q) \ddot{q}+\left\{\frac{1}{2} \dot{H}(q)+S(q, \dot{q})\right\} \dot{q}+g(q)=u
$$

に従う。ここに $H(q)$ は $4 \times 4$ の慣性行列であり, ラグ ランジアンを $L=K-P$ とすれば $K=(1 / 2) \dot{q}^{\mathrm{T}} H(q) \dot{q}$ 


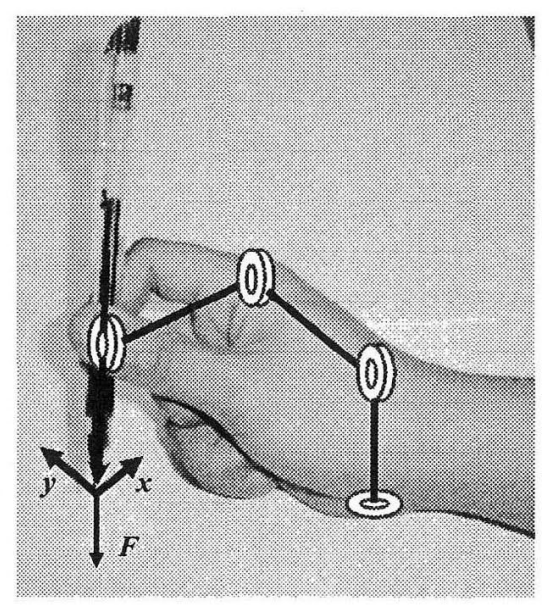

Fig. 1 Human handwriting

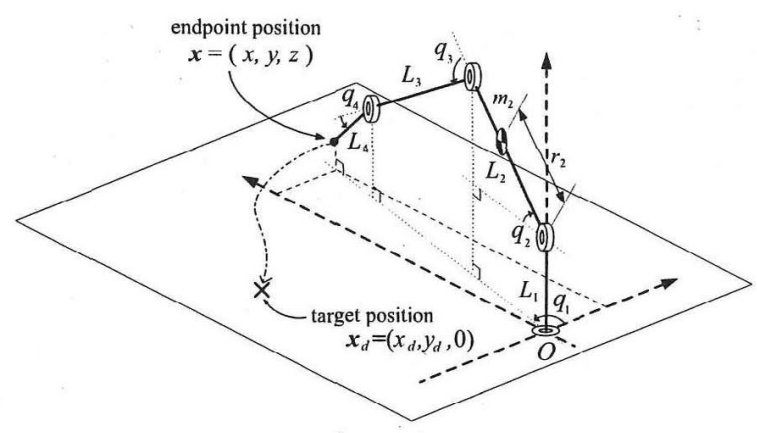

Fig. 2 A handwriting robot with four joints (four degrees of freedom)

であり， $g(q)$ は重力項である。なお，(1) 式の $S(q, \dot{q})$ は skew-symmetric である7).つぎに, ペン先の位置 $x$ $\left(=(x, y, z)^{\mathrm{T}}\right)$ を $q$ の成分で表わしておくと，つぎのよ うになる。

$$
\begin{aligned}
& z=\phi(q)=l_{1}+l_{2} \mathrm{~S}_{2}+l_{3} \mathrm{~S}_{23}+l_{4} \mathrm{~S}_{234} \\
& x=\varphi\left(q_{2}, q_{3}, q_{4}\right) \mathrm{c}_{1}, \quad y=\varphi\left(q_{2}, q_{3}, q_{4}\right) \mathrm{s}_{1}
\end{aligned}
$$

ここに

$$
\varphi=\sqrt{x^{2}+y^{2}}=l_{2} \mathrm{c}_{2}+l_{3} \mathrm{c}_{23}+l_{4} \mathrm{c}_{234}
$$

であり， $z$ は $q_{1}$ に無関係になることに注意しておきたい. なお，ここでは $\mathrm{s}_{23}=\sin \left(q_{2}+q_{3}\right), \mathrm{c}_{2}=\cos q_{2}$, などと略 記した。また，ポテンシャル関数は

$$
\begin{aligned}
P(q)= & g\left\{\left(m_{2} r_{2}+m_{3} l_{2}+m_{4} l_{2}\right) \mathrm{s}_{2}\right. \\
& +\left(m_{3} r_{3}+m_{4} l_{3}\right) \mathrm{s}_{23}+m_{4} r_{4} \mathrm{~s}_{234}
\end{aligned}
$$

と表わされ，重力項は $g(q)=\{\partial P(q) / \partial q\}^{\mathrm{T}}$ と表わされ，各 要素はつぎのようになる.

$$
\left\{\begin{aligned}
g_{1}(q)= & 0 \\
g_{2}(q)= & g\left\{\left(m_{2} r_{2}+m_{3} l_{2}+m_{4} l_{2}\right) \mathrm{c}_{2}\right. \\
& \left.+\left(m_{3} r_{3}+m_{4} l_{3}\right) \mathrm{c}_{23}+m_{4} s_{4} c_{234}\right\} \\
g_{3}(q)= & g\left\{\left(m_{3} r_{3}+m_{4} l_{3}\right) \mathrm{c}_{23}+m_{4} s_{4} \mathrm{c}_{234}\right\} \\
g_{4}(q)= & g m_{4} r_{4} \mathrm{c}_{234}
\end{aligned}\right.
$$

なお, $r_{i}$ は第 $i$ 関節の中心からリンク $i$ の質量中心までの 距離を表わし, $g$ は重力定数を表わす.

\section{3. 几長関節リーチングの新しい制御法}

圥長関節リーチングの制御には, 代表的な方法としてヤコ ビアン行列 $J(q)$ の擬似逆行列を用いる方法や，人為的な動 作指標を導入してそれを最小化することによって関節軌道を 一意的に求める方法，あるいは，制御入力を

$$
\begin{gathered}
u=H(q) J(q)^{+}\left(\ddot{x}_{d}-j(q) \dot{q}\right)+h(q, \dot{q}) \\
+\left(I_{4}-J^{+}(q) J(q)\right) v
\end{gathered}
$$

とする方法などが提案された。ここに (7) 式の $\ddot{x}$ は目標に 向かう手先加速度軌道, $h(q, \dot{q})$ は慣性項以外のす心゙ての非 線形項の直接補償項であり, $J^{+}(q)$ は $J(q)$ の擬似逆行列, $\boldsymbol{v}$ は導入した動作指標の最小化から求める.なお，(7) 式の 右辺の第四項は零化空間における制御と考えられるので, 手 先のカーテシアン系内の運動には影響を与えないとされた． ここでは, これらの伝統的な方法とは全く異なって, 最も単 純な制御法

$$
u=-C \dot{q}-k J^{\mathrm{T}}(q) \Delta x+Y(q) \hat{\Theta}
$$

を提案する。ここに $k$ はスカラ值のゲイン,$C$ はダンピ ングに関するゲイン行列, $\hat{\Theta} は$ 重力項の未知パラメター $\Theta=\left(m_{2} s_{2}+m_{3} l_{2}+m_{4} l_{2}, m_{3} s_{3}+m_{4} l_{3}, m_{4} s_{4}\right)^{\mathrm{T}}$ の推定 量, $Y(q)$ は回帰子と呼ばれる $4 \times 3$ の行列

$$
Y(q)=g\left(\begin{array}{ccc}
0 & 0 & 0 \\
\mathrm{c}_{2} & \mathrm{c}_{23} & \mathrm{c}_{234} \\
0 & \mathrm{c}_{23} & \mathrm{c}_{234} \\
0 & 0 & \mathrm{c}_{234}
\end{array}\right)
$$

である。なお， $\hat{\Theta}(t)$ はつぎのように因果律を満たす更新則 で実時間計算するとする。

$$
\begin{aligned}
\hat{\Theta}(t) & =\hat{\Theta}(0)-\int_{0}^{t} \eta^{-1} Y^{\mathrm{T}}(q(\tau)) s(\tau) \mathrm{d} \tau \\
s(t) & =\dot{q}(t)+C^{-1} k J^{\mathrm{T}}(q(t)) \Delta \boldsymbol{x}(t)
\end{aligned}
$$

ここで， $ク$ はリグレッサーゲインを表わすスカラ值である. (8) 式を (1) 式に代入し, つぎの閉ループダイナミクスを 得る.

$$
H \ddot{q}+\left(\frac{1}{2} \dot{H}+S\right) \dot{q}+C \dot{q}+k J^{\mathrm{T}} \Delta \boldsymbol{x}-Y \Delta \Theta=0
$$

ここに $\Delta \Theta=\hat{\Theta}-\Theta$ であり, $H$ や $S, J, Y$ が依存する従 属変数 $q$ や $\dot{q}$ の表記は, 混乱が起こらない限り, 省略する. 始めに, $\Delta \dot{\Theta}=\mathrm{d} \hat{\Theta} / \mathrm{d} t=-\eta^{-1} Y^{\mathrm{T}} s$ となることに注意し て, (12) 式の両辺と $s\left(=\dot{q}+k C^{-1} J^{\mathrm{T}} \Delta \boldsymbol{x}\right)$ との内積をとる と,つぎの式が成立する.

$$
\begin{aligned}
& \quad \frac{\mathrm{d}}{\mathrm{d} t} W=-\dot{q}^{\mathrm{T}} C \dot{q}-k^{2} \Delta \boldsymbol{x}^{\mathrm{T}} J C^{-1} J^{\mathrm{T}} \Delta \boldsymbol{x}+k h\left(J^{\mathrm{T}} \Delta \boldsymbol{x}, \dot{q}\right)(13) \\
& \text { ここに } \\
& \qquad \begin{aligned}
W= & \frac{1}{2} \dot{q}^{\mathrm{T}} H \dot{q}+k\|\Delta \boldsymbol{x}\|^{2}+\frac{\eta}{2}\|\Delta \Theta\|^{2} \\
& +k \dot{q}^{\mathrm{T}} H C^{-1} J^{\mathrm{T}} \Delta \boldsymbol{x}
\end{aligned}
\end{aligned}
$$




$$
\begin{aligned}
& h\left(J^{\mathrm{T}} \Delta \boldsymbol{x}, \dot{q}\right)=\dot{q}^{\mathrm{T}} H C^{-1} J^{\mathrm{T}} \Delta \dot{\boldsymbol{x}} \\
& \quad+\dot{q}^{\mathrm{T}}\left\{\left(\frac{1}{2} \dot{H}+S\right) C^{-1} J^{\mathrm{T}}+H C^{-1} \dot{J}\right\} \Delta \boldsymbol{x}
\end{aligned}
$$

である. $S$ や $\dot{H}, \dot{J}$ は $\dot{q}$ について線形斎次, かつ $\Delta \dot{\boldsymbol{x}}=J \dot{q}$

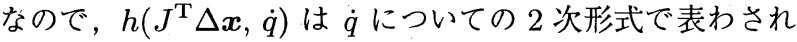
る.ここで，慣性行列 $H(q)$ を規定するロボットの物理パ ラメータを Table 1 に示しておく. $H(q)$ は対称正定であ り，各 $i j$ 成分は高々 $10^{-4}$ のオーダーであることがわかる. そこでダンピング係数 $c_{i}$ (対角行列 $C$ の第 $i$ 対角要素) を $10^{-2}$ のオーダーに取ったとしよう。また，Jの各成分は高々 $10^{-1}$ のオーダーである。このとき，不等式

$$
\begin{array}{rl}
-k \dot{q}^{\mathrm{T}} & H C^{-1} J^{\mathrm{T}} \Delta \boldsymbol{x} \\
& \leq \frac{1}{8} \dot{q}^{\mathrm{T}} H \dot{q}+2 k^{2} \Delta \boldsymbol{x} J C^{-1} H C^{-1} J^{\mathrm{T}} \Delta \boldsymbol{x}
\end{array}
$$

が成立することに注目すれば

$$
\begin{aligned}
W \geq & \frac{3}{8} \dot{q}^{\mathrm{T}} H \dot{q}+\frac{\eta}{2}\|\Delta \Theta\|^{2} \\
& +k \Delta \boldsymbol{x}^{\mathrm{T}}\left\{I_{3}-2 k J C^{-1} H C^{-1} J^{\mathrm{T}}\right\} \Delta \boldsymbol{x}
\end{aligned}
$$

となることがわかり, $C^{-1} H C^{-1}$ のすべての固有值は 1 の オーダー以下なので, $J C^{-1} H C^{-1} J^{\mathrm{T}}$ の三つの固有值は $10^{-2}$ のオーダーとなり,$k \leq 15.0$ のとき, $W$ は $\dot{q}, \Delta \boldsymbol{x}$, $\Delta \Theta$ について正定になる.つぎに, ペン先 $\boldsymbol{x}$ は $t=0$ のと き, 目標点 $\boldsymbol{x}_{d}$ から高々 $0.08[\mathrm{~m}]$ 以上は離れていない場合を 考えよう.このとき, $h\left(J^{\mathrm{T}} \Delta \boldsymbol{x}, \dot{q}\right)$ の各項を吟味すると，そ れら各項は $\|\dot{q}\|^{2}$.の約 $10^{-4}$ 倍のオーダーであることがわか る.したがって,$k \leq 15.0$ のとき，

$$
k h\left(J^{\mathrm{T}} \Delta \boldsymbol{x}, \dot{q}\right) \leq \frac{1}{4} \dot{q}^{\mathrm{T}} C \dot{q}
$$

として良い。こうして

$$
\frac{\mathrm{d}}{\mathrm{d} t} W \leq-\frac{3}{4} \dot{q}^{\mathrm{T}} C \dot{q}-k^{2} \Delta \boldsymbol{x}^{\mathrm{T}} J C^{-1} J^{\mathrm{T}} \Delta \boldsymbol{x}
$$

となり, $W$ が $\dot{q}, \Delta \Theta, \Delta \boldsymbol{x}$ について正定なので $\dot{q}, \Delta \Theta$, $\Delta \boldsymbol{x}$ は有界である。すなわち, $\dot{q}, \Delta \Theta, \Delta x$ の各ノルムはそ れぞれある值を越えない。つぎに，等号

$$
\begin{aligned}
\frac{\mathrm{d}}{\mathrm{d} t}( & \left.\beta \Delta \Theta^{\mathrm{T}} Y^{\mathrm{T}} C^{-1} H \dot{q}\right) \\
= & \beta \Delta \Theta^{\mathrm{T}} Y^{\mathrm{T}} C^{-1}\left\{Y \Delta \Theta-C s+\left(\frac{1}{2} \dot{H}-S\right) \dot{q}\right\} \\
& +\beta\left(\Delta \dot{\Theta}^{\mathrm{T}} Y^{\mathrm{T}}+\Delta \Theta^{\mathrm{T}} \dot{Y}\right) C^{-1} H \dot{q} \\
= & \frac{\mathrm{d}}{\mathrm{d} t}\left\{\frac{\eta \beta}{2}\|\Delta \Theta\|^{2}\right\}+\beta \Delta \Theta^{\mathrm{T}} Y^{\mathrm{T}} C^{-1} Y \Delta \Theta \\
& +\beta h(Y \Delta \Theta, \dot{q})
\end{aligned}
$$

が成立することに注目しよう。ここに $h(Y \Delta \Theta, \dot{q})$ は $h\left(J^{\mathrm{T}} \Delta \boldsymbol{x}, \dot{q}\right)$ の式で $J^{\mathrm{T}} \Delta \boldsymbol{x}$ を $Y \Delta \Theta$ に置き換えて作られ た. そこでスカラー関数 $V$ をつぎのように定義する.

$$
\begin{aligned}
V= & W+\frac{\eta \beta}{2}\|\Delta \Theta\|^{2}-\beta \Delta \Theta^{\mathrm{T}} Y^{\mathrm{T}} C^{-1} H \dot{q} \\
= & \frac{1}{2} \dot{q}^{\mathrm{T}} H \dot{q}+k\|\Delta \boldsymbol{x}\|^{2}+\frac{\eta(1+\beta)}{2}\|\Delta \Theta\|^{2} \\
& +\dot{q}^{\mathrm{T}} H C^{-1}\left\{k J^{\mathrm{T}} \Delta \boldsymbol{x}-\beta Y \Delta \Theta\right\}
\end{aligned}
$$

Table 1 Link parameters

\begin{tabular}{c|c|c}
\hline $\begin{array}{c}\text { Mass } \\
{[\mathrm{kg}]}\end{array}$ & $\begin{array}{c}\text { Inertia moment } \\
{\left[\mathrm{kgm}^{2}\right]}\end{array}$ & $\begin{array}{c}\text { Link length } \\
{[\mathrm{m}]}\end{array}$ \\
\hline$m_{1}=0.02409$ & $I_{1 z}=0.040 \times 10^{-5}$ & $l_{1}=0.010$ \\
\hline$m_{2}=0.04015$ & $I_{2 x}=I_{2 y}=0.870 \times 10^{-5}$ & $l_{2}=0.050$ \\
\hline$m_{3}=0.04015$ & $I_{3 x}=I_{3 y}=0.870 \times 10^{-5}$ & $l_{3}=0.050$ \\
\hline$m_{4}=0.02409$ & $I_{4 x}=I_{4 y}=0.201 \times 10^{-5}$ & $l_{4}=0.030$ \\
\hline
\end{tabular}

そこで，不等式

$$
\begin{aligned}
& -\beta \Delta \Theta^{\mathrm{T}} Y^{\mathrm{T}} C^{-1} H \dot{q} \\
& \geq-\frac{1}{8} \dot{q}^{\mathrm{T}} H \dot{q}-2 \beta^{2} \Delta \Theta^{\mathrm{T}} Y^{\mathrm{T}} C^{-1} H C^{-1} Y \Delta \Theta
\end{aligned}
$$

が成立することに注目し，(21)式に (16)，(22) 式を代入す ると，次式を得る。

$$
\begin{aligned}
V & \geq \frac{1}{4} \dot{q}^{\mathrm{T}} H \dot{q}+k \Delta \boldsymbol{x}^{\mathrm{T}}\left\{I_{3}-2 k J C^{-1} H C^{-1} J^{\mathrm{T}}\right\} \Delta \boldsymbol{x} \\
& +\frac{\eta(1+\beta)}{2} \Delta \Theta^{\mathrm{T}}\left\{I_{3}-\frac{4 \beta^{2}}{\eta(1+\beta)} Y^{\mathrm{T}} C^{-1} H C^{-1} Y\right\} \Delta \Theta
\end{aligned}
$$

また，(19) 式の両辺から (20) 式の両辺をそれぞれ引くこと により, 式

$$
\begin{aligned}
\dot{V} \leq & -\frac{3}{4} \dot{q}^{\mathrm{T}} C \dot{q}-k^{2} \Delta \boldsymbol{x}^{\mathrm{T}} J C^{-1} J^{\mathrm{T}} \Delta \boldsymbol{x} \\
& -\beta \Delta \Theta^{\mathrm{T}} Y^{\mathrm{T}} C^{-1} Y \Delta \Theta-\beta h(Y \Delta \Theta, \dot{q})
\end{aligned}
$$

を得る。 $\Theta$ の各成分は Table 1 から高々 $10^{-3}$ のオーダー であり，Yの成分の絶対值は高々 $10^{1}$ のオーダーなので, $h(Y \Delta \Theta, \dot{q})$ は $\|\dot{q}\|^{2}$ の $10^{-4}$ 倍のオーダーになる。こうし て, $\beta \leq 1$ である限り, $\beta h(Y \Delta \Theta, \dot{q})$ の絶対值は $(1 / 4) \dot{q}^{\mathrm{T}} C \dot{q}$ を越えない。こうして，(24) 式は不等式

$$
\begin{aligned}
\dot{V} \leq & -\frac{1}{2} \dot{q}^{\mathrm{T}} C \dot{q}-k^{2} \Delta \boldsymbol{x}^{\mathrm{T}} J C^{-1} J^{\mathrm{T}} \Delta \boldsymbol{x} \\
& -\beta \Delta \Theta^{\mathrm{T}} Y^{\mathrm{T}} C^{-1} Y \Delta \Theta
\end{aligned}
$$

\section{に帰着する。}

(23) と (25) 式からつぎの結果が得られる。もし， $\eta$ を $O\left(10^{2}\right), \beta$ を 0.2 以下に選べば，(23) 式の右辺の第三項は $\Delta \Theta$ について正定になるので, $V$ は $\dot{q}, \Delta \boldsymbol{x}, \Delta \Theta$ について

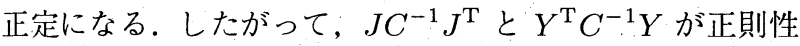
を失わない限り， $\dot{q}, \Delta \boldsymbol{x}, \Delta \Theta$ は 2 乗可積分になる。さら に, $\ddot{q}$ の有界性から $\dot{q} や \Delta \boldsymbol{x}, \Delta \Theta$ は一様連続になり, Barbalat の補題から, $t \rightarrow \infty$ のとき $\dot{q}(t) \rightarrow 0, \Delta \boldsymbol{x}(t) \rightarrow 0$, $\Delta \Theta(t) \rightarrow 0$ となることがわかる. しかし， $\dot{q}$ は 2 乗可積分

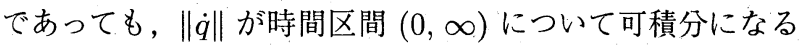
とは限らない，すなわち，Seraji ${ }^{8)}$ が主張するように，圥長 性に特有の self-motion が起こるかもしれない。 そこで，こ こで取り扱うシステムについては, self-motion が起こらな いことを示す必要がある。この節の最後に， $\gamma>0$ をパラメ ターとして，(21) と (25) 式から次式が得られることに注意 しておく

$$
\begin{aligned}
\dot{V} \leq & -\gamma V-\frac{1}{2} \dot{q}^{\mathrm{T}}(C-\gamma H) \dot{q} \\
& -k \Delta \boldsymbol{x}^{\mathrm{T}}\left\{k J C^{-1} J^{\mathrm{T}}-\gamma I_{3}\right\} \Delta \boldsymbol{x}
\end{aligned}
$$




$$
\begin{aligned}
& -\beta \Delta \Theta^{\mathrm{T}}\left\{Y^{\mathrm{T}} C^{-1} Y-\frac{\gamma \eta(1+\beta)}{2 \beta} I_{3}\right\} \Delta \Theta \\
& +\gamma \dot{q} H^{-1} C^{-1}\left\{k J^{\mathrm{T}} \Delta x-\beta Y \Delta \Theta\right\}
\end{aligned}
$$

また，不等式

$$
\left\{\begin{array}{l}
\gamma k \dot{q}^{\mathrm{T}} H C^{-1} J^{\mathrm{T}} \Delta \boldsymbol{x} \\
\leq(1 / 2) \gamma k \dot{q}^{\mathrm{T}} H C^{-1} H \dot{q}+(\gamma k / 2) \Delta \boldsymbol{x} J C^{-1} J^{\mathrm{T}} \boldsymbol{x} \\
-\gamma \beta \dot{q}^{\mathrm{T}} H C^{-1} Y \Delta \Theta \\
\leq 2 \gamma \beta \dot{q}^{\mathrm{T}} H C^{-1} H \dot{q}+(\gamma \beta / 8) \Delta \Theta Y^{\mathrm{T}} C^{-1} Y \Delta \Theta
\end{array}\right.
$$

に注意すると，(26) 式はつぎのように書き直せる.

$$
\begin{aligned}
\dot{V} \leq & -\gamma V-\frac{1}{2} \dot{q}^{\mathrm{T}}\left\{C-\gamma H-\gamma(k+4 \beta) H C^{-1} H\right\} \dot{q} \\
& -k \Delta \boldsymbol{x}\left\{\left(k-\frac{\gamma}{2}\right) J C^{-1} J^{\mathrm{T}}-\gamma I_{3}\right\} \Delta \boldsymbol{x} \\
& -\beta \Delta \Theta^{\mathrm{T}}\left\{\left(1-\frac{\gamma \beta}{8}\right) Y^{\mathrm{T}} C^{-1} Y-\frac{\gamma \eta(1+\beta)}{2 \beta} I_{3}\right\} \Delta \Theta
\end{aligned}
$$

\section{4. 多様体上の安定性と可遷移性}

圥長多関節リーチングでは, 手先 (ペン先) の目標位置 $\boldsymbol{x}(q)=\boldsymbol{x}_{d}$ を実現する姿勢を表わす関節ベクトル $\boldsymbol{q}$ は無限 にあり得て, 状態空間 $(q, \dot{q}) \in R^{8}$ の中で 1 次元の多様体

$$
M_{1}=\left\{(q, \dot{q}): \boldsymbol{x}(q)=\boldsymbol{x}_{d}, \dot{q}=0\right\}
$$

を構成する. そこで $M_{1}$ 上にある一点 $\left(q^{0}, 0\right) \in M_{1}$ を指定 したとき，三つの組 $\left\{q(t)=q^{0}, \dot{q}(t)=0, \Delta \Theta(t)=0\right\}$ は閉 ループダイナミクスを表わす (12) 式の一つの平衡解を表わ す.この平衡解の安定性をつぎのように定義しょう ${ }^{9)}$.

多様体上の安定性 任意の $\varepsilon>0$ に対して, $\varepsilon$ に依存す る三つの数 $\delta_{0}(\varepsilon)>0, \delta_{1}(\varepsilon)>0, \delta_{2}(\varepsilon)>0$ が存在して, 三つの式

$$
\left\|q(0)-q^{0}\right\|_{K} \leq \delta_{0}(\varepsilon),\|\dot{q}(0)\|_{K}<\delta_{1}(\varepsilon),\|\Delta \Theta(0)\| \leq \delta_{2}(\varepsilon)
$$
を満足する任意の初期条件 $(q(0), \dot{q}(0), \Delta \Theta(0))$ から出発 した閉ループダイナミクス ((12) 式) の解軌道が, 任意の $t \geq 0$ で領域

$$
D_{\varepsilon}=\left\{(q, \dot{q}):\left\|q(t)-q^{0}\right\|_{K} \leq \varepsilon,\|\dot{q}(t)\|_{K} \leq \varepsilon\right\}
$$

にとどまり，かつ $t \rightarrow \infty$ のとき $M_{1}$ 上のある一点に収束 するとき, 参照状態 $\left(q^{0}, 0\right)$ は多様体上安定であるという.

この定義で, 関節ベクトル $q$ や関節角速度ベクトル $\dot{q}$ の ノルムはつぎのように定義する。

$$
\begin{aligned}
\left\|q-q^{0}\right\|_{K} & =\left\{\frac{1}{2}\left(q-q^{0}\right)^{\mathrm{T}} H(q)\left(q-q^{0}\right)\right\}^{1 / 2} \\
\|\dot{q}\|_{K} & =\left\{\frac{1}{2} \dot{q}^{\mathrm{T}} H(q) \dot{q}\right\}^{1 / 2}
\end{aligned}
$$

ただし, $\|\Delta \boldsymbol{x}(t)\| や\|\Delta \Theta(t)\|$ などは普通のユークリッド， ルムを表わすとする。

なお, 重力項のパラメターベクトル $\Theta$ が真值に十分近く

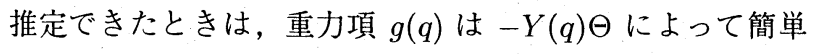
に計算できるので, 制御入力を

$$
u=-C \dot{q}-k J^{\mathrm{T}}(q) \Delta \boldsymbol{x}+g(q)
$$

Table 2 Initial conditions

\begin{tabular}{c||c|c|c|c}
\hline \multicolumn{1}{c||}{$\begin{array}{c}\text { Parameter } \\
\text { [Unit] }\end{array}$} & \multicolumn{4}{c}{ Initial posture $\boldsymbol{q}(\tilde{0})$} \\
\hline Variable & $q_{1}$ & $q_{2}$ & $q_{3}$ & $q_{4}$ \\
\hline Value & 70.0 & 40.0 & -30.0 & -30.0 \\
\hline
\end{tabular}

Table 3 Target conditions

\begin{tabular}{c||c|c|c}
\hline \multicolumn{1}{c||}{$\begin{array}{c}\text { Parameter } \\
\text { [Unit] }\end{array}$} & \multicolumn{3}{c}{ Target position $\boldsymbol{x}_{d}$} \\
[m]
\end{tabular}

と定める．このとき，閉ループダイナミクスは，これを (1) 式に代入することにより，つぎのようになる。

$$
H \ddot{q}+\left\{\frac{1}{2} \dot{H}+S+C\right\} \dot{q}+J^{\mathrm{T}} k \Delta \boldsymbol{x}=0
$$

強可遷移性 $^{10)}$ 初期状態 $(q(0), \dot{q}(0)=0)$ 加出発し た (32) 式の解 $(q(t), \dot{q}(t))$ が下記の不等式を満足しつつ, $t \rightarrow \infty$ のとき $M_{1}$ 上のある状態に収束するならば, その初 期状態は self-motion を起こさずに $M_{1}$ に可遷移であるとい う（あるいは，単に $M_{1}$ に強可遷移であるという).

$$
l_{i}\left|q_{i}(t)-q_{i}(0)\right| \leq \alpha \pi \sqrt{k}\|\Delta \boldsymbol{x}(0)\|, \quad i=1, \cdots, 4 \text { (33) }
$$

ここに $\alpha$ は 1 のオーダーであり， $l_{i}$ は Table 1 に示す各リ ンクの長さを表わす.

可遷移性 ある範囲の初期パラメター推定䛊差 $\Delta \Theta(0)$ のもとで, 初期状態 $(q(0), 0)$ から出発した $(12)$ 式の解 $(q(t), \dot{q}(t))$ がつぎの式を满足しつつ, $t \rightarrow \infty$ のとき $M_{1}$ の ある状態に収束するならば, $(q(0), 0)$ は $M_{1}$ に可遷移であ るという。

$$
\|q(t)-q(0)\|_{K} \leq d \sqrt{k}\{\|\Delta \boldsymbol{x}(0)\|+\mu\|\Delta \Theta(0)\|\}(34)
$$

ここに $d$ は高々 $O\left(10^{2}\right)$ の正の定数であり, $\mu=\sqrt{\eta / k}$, $q(t)-q(0)$ のノルムは $(29)$ 式で $q=q(t), q^{0}=q(0)$ とし て定義するものとする.

ここでは，ペン先が Fig. 2 に示すような普通の姿勢から， ペン先が $x y$ 平面を通り越すようなオーバーシュートする ことなく(つまり,$z<0$ となることなく,$x y$ 平面の点 $\boldsymbol{x}_{d}=\left(x_{d}, y_{d}, 0\right)$ に遷移できるようなスチッフネス $k>0$ とダンピング係数の組 $\left\{c_{1}, c_{2}, c_{3}, c_{4}\right\}$ がありうることを示 そう.ただし $x_{d}$ の原点 $O$ からの距離はペンの角度 $q_{0}$ $\left(=q_{2}+q_{3}+q_{4}\right)$ が水平面と直角になるようなことはなく, ほほ $45^{\circ} \sim 75^{\circ}$ にとれるような姿勢が実現できるようにし たい.すでに，人間の大人のリーチング運動や Table 1 に基 づく書字ロボットについて解析したように ${ }^{4)}$, ダンピングゲ イン行列 $C$ は $t=0$ のときの慣性行列 $H(0)$ の平方根行列 のオーダーに取ると良いことが示されている ${ }^{3)}$.ここでは， 第 4 リンクに相当するペンの慣性モーメントが比較的小さ いことを考慮して，

$$
c_{1}=0.02, c_{2}=0.035, c_{3}=0.012, c_{4}=0.004 \text { (35) }
$$

と選び, $k=15.0$ [Nms] としたときの数值シミュレーショ ン結果を Fig. 3〜12 に示す.ここに初期姿勢は Table 2 


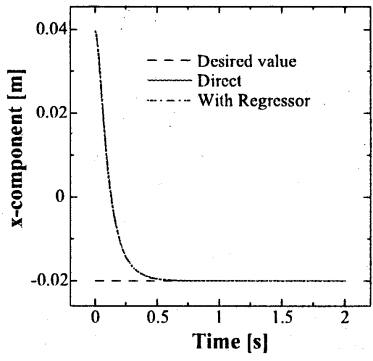

Fig. 3 Responses of $x$

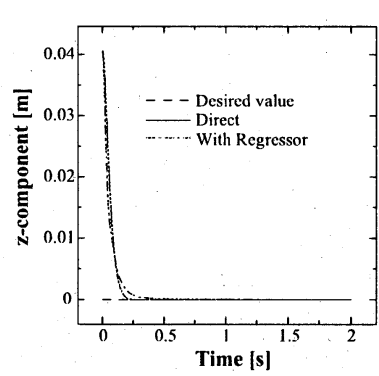

Fig. 5 Responses of $z$

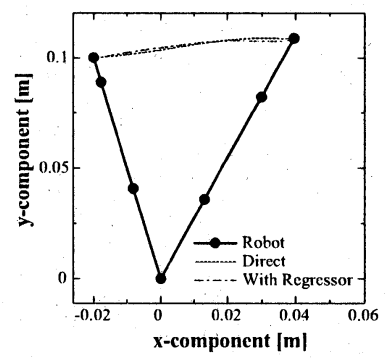

Fig. 7 Responses in $x y$ plane

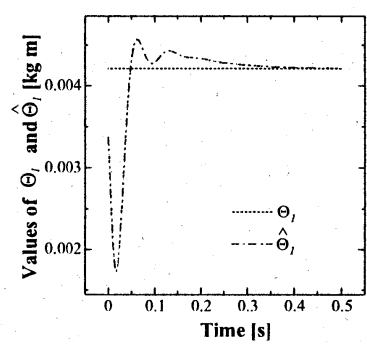

Fig. 9 Responses of $\Theta_{1}$ and $\hat{\Theta}_{1}$

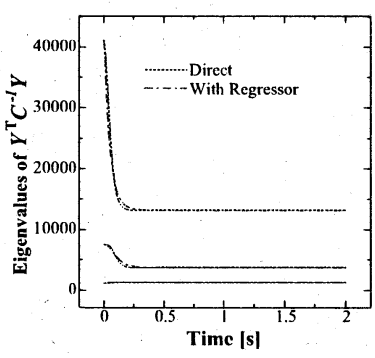

Fig. 11 Eigenvalues of $Y^{\mathrm{T}} C^{-1} Y$

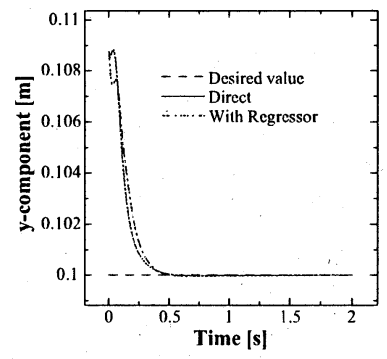

Fig. 4 Responses of $y$

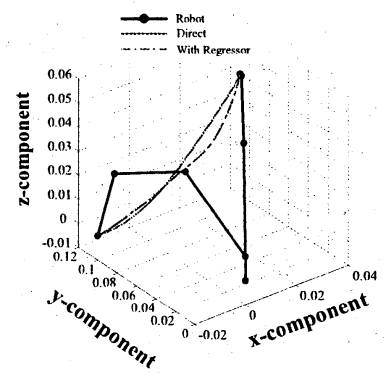

Fig. 6 Movements of the robot

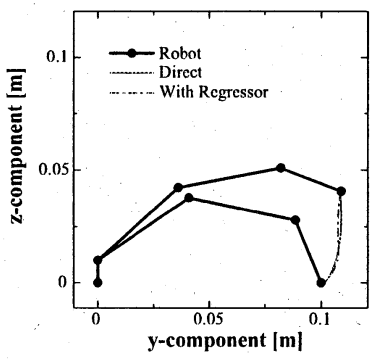

Fig. 8 Responses in $y z$ plane

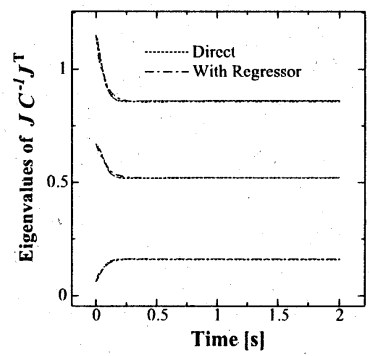

Fig. 10 Eigenvalues of $J C^{-1} J^{\mathrm{T}}$

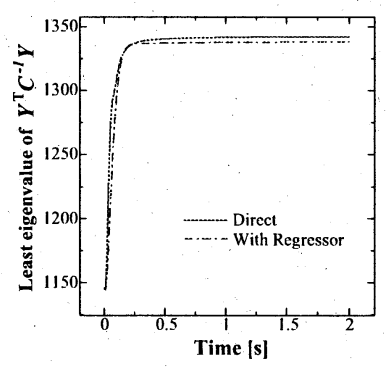

Fig. 12 Responses of the least eigenvalue
に, ペン先の目標点は Table 3 で与えたが, 重力項の未知 パラメター $\Theta$ の推定量ベクトルの初期值 $\hat{\Theta}(0)$ はそれぞれ の真值の $80 \%$ の值を与え, また, $r_{i}=l_{i} / 2(i=2,3,4)$ と した. Fig. 9 を除いて, Fig. 3 から Fig. 12 において“With Regressor” と記した軌跡が (12) 式の閉ループダイナミクス に基づいて得られたシミュレーション結果であり，“Direct” と称した軌跡は (32) 式の数值解である.Fig. 9 から, 重力 項の推定量 $\hat{\Theta}_{i}(t)$ はわずか 0.4 秒で真值に収束し,この初 期段階の誤差がわずかに $y$ の軌道に乱れを生じさせること が見える.また, Fig.5の $z$ の軌道でわかるように, ペン 先は途中で $x y$ 平面を上から突き抜けることはなく（オー バーシュートが起こっていない), $z=0$ ( $x y$ 平面) に指数 関数的に収束していることがわかる：なお，Fig. 6〜8では ロボットの初期姿勢と $t \rightarrow \infty$ としたときの終了時の姿勢, および，ペン先の軌道のみが表わされており，途中でロボッ トの姿勢がどのように推移したかは表わしていない. 言い換 えれば, 罙長自由度系に特有の self-motion ${ }^{8)}$ が起こってい るかどうかこれらの数值結果からは明らかでない. そこで, 可遷移性を理論的に保証しておくことが重要になる.

《定理 1》 (12) 式の閉ループダイナミクスについて, $k=$ $15.0[\mathrm{Nms}], \eta=100$ としかつ (35) 式のダンピング係数 を与えたとき, Table 2 の初期条件 $(\dot{q}(0)=0$ とする) か ら Table 3 への手先目標位置へのリーチングは可遷移であ る.たたし, 運動中 $3 \times 3$ の行列 $Y^{\mathrm{T}} C^{-1} Y$ の最小固有値 は $1.1 \times 10^{3}$ を下迴らず (Fig. 11, 12 参照)， $\Delta \Theta(0)$ の各 成分は $\Theta$ の対応する成分の真值の約 $20 \%$ の誤差範囲にある とする。

（証明） (28) 式で $\beta=0.2, \gamma=0.8(=4 / 5)$ とすれば, 三 つの \{\}の中味はそれぞれ正定行列になることがわかる．た とえば, $J C^{-1} J^{\mathrm{T}} \cdot$ の最小固有値は Fig. 10 から 0.06 以下に なることはない.したがって, (28) 式より $\dot{V} \leq-(4 / 5) V$ となり,このことと $\dot{q}(0)=0$ であることから, 次式が成立 する

$$
\begin{aligned}
V(t) & \leq V(0) e^{-4 t / 5} \\
& =k\left\{\|\Delta \boldsymbol{x}(0)\|^{2}+\mu^{2}\|\Delta \Theta(0)\|\right\} e^{-4 t / 5}
\end{aligned}
$$

他方, 不等式 (23) の右辺の二つの括弧 \{ \}の中味を吟味する と, $C$ はほぼ $H^{1 / 2}(q(0))$ を下迴らないように選んでいるの で, $k \leq 15$ のとき最初の \{\} の中味は非負定になることがわ かる (Fig.13 参照). また, $y=C^{-1}\left\{k J^{\mathrm{T}} \Delta \boldsymbol{x}-\beta Y \Delta \Theta\right\}$ とおき，不等式関係 $2|a b| \leq a^{2}+b^{2}$ を適用することにより， 不等式

$$
\begin{aligned}
& V \geq \frac{1}{2}(\dot{q}+y)^{\mathrm{T}} H(\dot{q}+y)+\frac{1}{2} y^{\mathrm{T}} H y \\
& +k \Delta \boldsymbol{x}^{\mathrm{T}}\left\{I_{3}-2 k J C^{-1} H C^{-1} J^{\mathrm{T}}\right\} \Delta \boldsymbol{x} \\
& +\frac{\eta(1+\beta)}{2} \Delta \Theta\left\{I_{3}-\frac{4 \beta^{2}}{\eta(1+\beta)} Y^{\mathrm{T}} C^{-1} H C^{-1} Y\right\} \Delta \Theta
\end{aligned}
$$

が成立することが示せる．右辺第 3 項は上で述べたように 非負定であるが，第 4 項の \{\}の中は (23) 式と第二の \{\} 


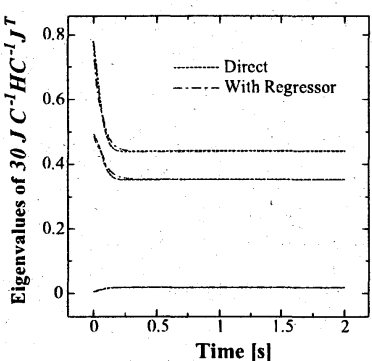

Fig. 13 Transient responses

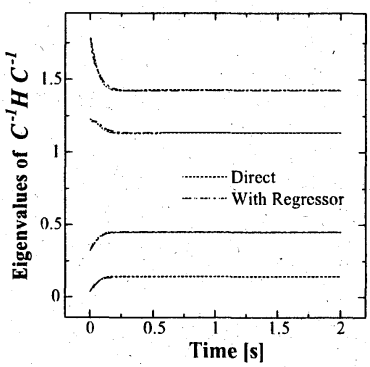

Fig. 15 Transient responses

の中と同じであり， $\beta=0.2, \eta=100$ のとき非負定である

(Fig. 14 参照)。こうして, (36)と (37) 式からつぎの二つ の不等式が成立する.

$$
\begin{aligned}
& \frac{1}{\sqrt{2}}\left\|H^{1 / 2}(\dot{q}+y)\right\| \leq V^{1 / 2}(t) \\
& \quad \leq \sqrt{k}\{\|\Delta \boldsymbol{x}(0)\|+\mu\|\Delta \Theta(0)\|\} e^{-2 t / 5} \\
& \frac{1}{\sqrt{2}}\left\|H^{1 / 2} y\right\| \leq V^{1 / 2}(t) \\
& \quad \leq \sqrt{k}\{\|\Delta \boldsymbol{x}(0)\|+\mu\|\Delta \Theta(0)\|\} e^{-2 t / 5}
\end{aligned}
$$

つぎに,ダンピング係数行列 $C$ はほほ $H(q(0))$ の平方根行 列を近似するように選んだので，運動中のどんな姿勢 $q$ に วいても

$$
r_{m} C \leq H^{1 / 2}(q) \leq r_{M} C
$$

となるような正定数 $r_{m}, r_{M}$ が存在する.実際には， $C^{-1} H(q) C^{-1}$ の固有值の動きは Fig. 15 のようになり, $r_{m}$ をなるべく大きく, $r_{M}$ は小さく選べば，それらの比 $r_{M} / r_{m}$ は $\sqrt{60}$ を越えることはない（Fig. 15 から $r_{m}=\sqrt{0.033}$, $r_{M}=\sqrt{1.8}$ と選べる).これらのことから，つぎの式が成立 する。

$$
\begin{aligned}
& \|q(t)-q(0)\|_{K} \\
& =\left[\frac{1}{2}\{q(t)-q(0)\}^{\mathrm{T}} H(q(t))\{q(t)-q(0)\}\right]^{1 / 2} \\
& \leq \frac{r_{M}}{\sqrt{2}}\|C(q(t)-q(0))\| \\
& =\frac{r_{M}}{\sqrt{2}}\left\|\int_{0}^{t} C \dot{q}(\tau) \mathrm{d} \tau\right\| \\
& \leq \frac{r_{M}}{\sqrt{2} r_{m}} \int_{0}^{t}\left\|H^{1 / 2}(q) \dot{q}\right\| \mathrm{d} \tau
\end{aligned}
$$

そこで, $y=C^{-1}\left(k J^{\mathrm{T}} \Delta \boldsymbol{x}-Y \Delta \Theta\right)$ とおくと, (38), (39)

と (41) 式より,

$$
\begin{aligned}
& \|q(t)-q(0)\|_{K} \leq \frac{r_{M}}{\sqrt{2} r_{m}} \int_{0}^{t}\left\|H^{1 / 2}\{(\dot{q}+y)-(y)\}\right\| \mathrm{d} \tau \\
& \leq \frac{r_{M}}{\sqrt{2} r_{m}} \int_{0}^{t}\left\{\left\|H^{1 / 2}(\dot{q}+y)\right\|+\left\|H^{1 / 2} y\right\|\right\} \mathrm{d} \tau \\
& \leq \frac{2 r_{M}}{r_{m}} \sqrt{k}\{\|\Delta \boldsymbol{x}(0)\|+\mu\|\Delta \Theta(0)\|\} \int_{0}^{t} e^{-2 \tau / 5} \mathrm{~d} \tau \\
& \leq \frac{5 r_{M}}{r_{m}} \sqrt{k}\{\|\Delta \boldsymbol{x}(0)\|+\mu\|\Delta \Theta(0)\|\}
\end{aligned}
$$

ここに $r_{M} / r_{m}$ は $\sqrt{60}$ を越えないので, $d=5 r_{M} / r_{m}$ とお くと, $d$ は高々 $O\left(10^{2}\right)$ となって, (42) 式は (34) 式に一致 し, 定理は証明された。

《定理 2》 (31) 式の制御則を用いた (32) 式の閉ループダイ ナミクスについて, Table 2 の初期条件から Table 3 への手 先目標位置へのリーチングは強可遷移である（すなわち，ぺ ン先は self-motionを起こすことなく $M_{1}$ に可遷移).ここ に $k=15.0, \eta=100$ とする.

（証明）始めに，不等式

$$
\begin{aligned}
V & =W=\frac{1}{2} \dot{q}^{\mathrm{T}} H \dot{q}+k\|\Delta \boldsymbol{x}\|^{2}+\dot{q}^{\mathrm{T}} H C^{-1} k J^{\mathrm{T}} \Delta \boldsymbol{x} \\
& \geq k \Delta \boldsymbol{x}^{\mathrm{T}}\left\{I_{3}-\frac{k}{2} J C^{-1} H C^{-1} J^{\mathrm{T}}\right\} \Delta \boldsymbol{x} \\
& =\frac{3 k}{4}\|\Delta \boldsymbol{x}\|^{2}+\frac{k}{4} \Delta \boldsymbol{x}^{\mathrm{T}}\left\{I_{3}-2 k J C^{-1} H C^{-1} J^{\mathrm{T}}\right\} \Delta \boldsymbol{x} \\
& \geq \frac{3}{4} k\|\Delta \boldsymbol{x}\|^{2}
\end{aligned}
$$

が成立することから，

$$
\sqrt{3 k / 4}\|\Delta \boldsymbol{x}(t)\| \leq V^{1 / 2}(t) \leq \sqrt{k}\|\Delta \boldsymbol{x}(0)\| e^{-2 t / 5}
$$

となり,これより不等式

$$
\|\Delta \boldsymbol{x}(t)\| \leq \frac{2}{\sqrt{3}}\|\Delta \boldsymbol{x}(0)\| e^{-2 t / 5}
$$

が成立することに注意する，つぎに，閉ループダイナミクス の $(32)$ 式の左側から $C^{-1}$ を掛け，区間 $(0, t)$ で積分する と $(\dot{q}(0)=0$ であることに注意して $)$,

$$
\begin{gathered}
C^{-1} H(q(t)) \dot{q}(t)+(q(t)-q(0)) \\
+\int_{0}^{t} k C^{-1} J^{\mathrm{T}}(q(\tau)) \Delta \boldsymbol{x}(\tau) \mathrm{d} \tau \\
=-\int_{0}^{t} C^{-1}\left(\frac{1}{2} \dot{H}+S\right) \dot{q} \mathrm{~d} \tau
\end{gathered}
$$

となることに注目する。ここでヤコビアン行列 $J(q)$ を $J=\left(J_{1}, \cdots, J_{4}\right), J_{i}=\partial \boldsymbol{x} / \partial q_{i}(i=1, \cdots, 4)$ と表わせば, たとえば, $i=4$ に対応して, 式

$$
\begin{aligned}
& \left|q_{4}(t)-\dot{q}_{4}(0)\right| \leq k c_{4}^{-1} \int_{0}^{t}\left|J_{4}^{\mathrm{T}} \Delta \boldsymbol{x}\right| \mathrm{d} \tau \\
& +\left\|C^{-1} H(q(t)) \dot{q}(t)\right\|+\int_{0}^{t}\left\|C^{-1}\left(\frac{1}{2} \dot{H}+S\right) \dot{q}\right\| \mathrm{d} \tau(47)
\end{aligned}
$$

が成立する．他方，(17) 式から（今, $\Delta \Theta=0$ と考えてい るので),

$$
V=W \geq \frac{3}{8} \dot{q}^{\mathrm{T}} H(q) \dot{q}
$$


であり,このことと $(40)$ 式から

$$
\begin{aligned}
\left\|C^{-1} H \dot{q}\right\| & \leq r_{M}\left\|H^{1 / 2} \dot{q}\right\|=\sqrt{8 / 3} r_{M} \sqrt{(3 / 8) \dot{q}^{\mathrm{T}} H \dot{q}} \\
& \leq \sqrt{3} r_{M} V^{1 / 2}(t)
\end{aligned}
$$

となる.また, $C^{-1}\left(\frac{1}{2} \dot{H}+S\right) \dot{q}$ は $\dot{q}$ の成分に関して 2 次 式であり, 係数は高々 $H^{1 / 2}(q)$ の最大固有值のオーダーな ので,

$$
\int_{0}^{t^{\prime}}\left\|C^{-1}\left(\frac{1}{2} \dot{H}+S\right) \dot{q}\right\| \mathrm{d} \tau \leq \delta_{0} \int_{0}^{t} \dot{q}^{\mathrm{T}} C \dot{q} \mathrm{~d} \tau
$$

であるような定数 $\delta_{0}>0$ が存在し，それは 1 のオーダー である.ここでは大きめに見積もって $\delta_{0}=5.0$ としておく. こうして (46) 式は

$$
\begin{aligned}
& l_{4}\left|q_{4}(t)-q_{4}(0)\right| \leq \frac{l_{4}}{c_{4}} k \int_{0}^{t}\left\|J_{4}\right\|\|\Delta \boldsymbol{x}\| \mathrm{d} \tau \\
& +l_{4}\left\{\sqrt{3} r_{M} V^{1 / 2}(t)+\delta_{0} \int_{0}^{t} \dot{q}^{\mathrm{T}} C \dot{q} \mathrm{~d} \tau\right\}
\end{aligned}
$$

となる.ここで $\left\|l_{4}\right\| \leq l_{4}$ であり, (25) 式から $(1 / 2) \dot{q}^{\mathrm{T}} C \dot{q}$ の積分は $V(0)\left(=k\|\Delta \boldsymbol{x}(0)\|^{2}\right)$ を越えないことに注意すれ ば, (45) 式から

$$
\begin{aligned}
& l_{4}\left|q_{4}(t)-q_{4}(0)\right| \leq \frac{l_{4}^{2}}{c_{4}} k \frac{2}{\sqrt{3}}\|\Delta \boldsymbol{x}(0)\| \int_{0}^{t} e^{-2 \tau / 5} \mathrm{~d} \tau \\
&+l_{4}\left(\sqrt{3} r_{M} V^{1 / 2}(0)+2 \delta_{0} V(0)\right) \\
& \leq \frac{0.03^{2} \sqrt{k}}{0.003} \cdot \frac{5}{\sqrt{3}} \cdot \sqrt{k}\|\Delta \boldsymbol{x}(0)\| \\
&+0.03\left(\sqrt{3} \cdot \sqrt{1.8} V^{1 / 2}(0)+10.0 V(0)\right) \\
&= 1.5 \sqrt{5} \cdot \sqrt{k}\|\Delta \boldsymbol{x}(0)\| \\
&+\left(0.1+0.3 V^{1 / 2}(0)\right) \sqrt{k}\|\Delta \boldsymbol{x}(0)\| \\
& \leq(3.354+0.2) \cdot \sqrt{k}\|\Delta \boldsymbol{x}(0)\|
\end{aligned}
$$

となり，i=4のときの (33) 式が $\alpha=(3.554) / \pi$ で成立し， $\alpha$ は高々 1 のオーダーであることが示された．同様にして， $i=1,2,3$ の (33) 式も示すことができるが, ここでは省略 する.

ここでは, 基本的な不等式をタイトにとるために, 行列 $J C^{-1} J^{\mathrm{T}}$ の最小固有値の下限や, $J C^{-1} H C^{-1} J^{\mathrm{T}}$ の最大固 有値の上限の算出にシミュレーション結果を使った. 全くシ ミュレーションを行なうことなく, (40) 式を満たす $r_{m}, r_{M}$ を定め, 上述の二つの行列の最小固有值, 最大固有値を見積 もることは可能である。しかし, その結果, 定理 2 の証明で $\gamma$ は小さく選ばなくてはならず，結果的に (33) 式を満たす $\alpha$ は大きめになってしまう.

\section{5. 重力補償に関する考察}

手書きロボットの目標点をずっと手前に取ると, ペンの水 平面からの角度 $\left(q_{2}+q_{3}+q_{4}\right)$ は $-\pi / 2$ を越える瞬間が生じ, (9) 式の回㷌子がランク落ちする. 実際, 初期姿勢とダンピ ング係数を同じにして, 目標点だけを変えて行なったシミュ レーション結果を Fig. 16, 17 に示す.この場合, ペン先は

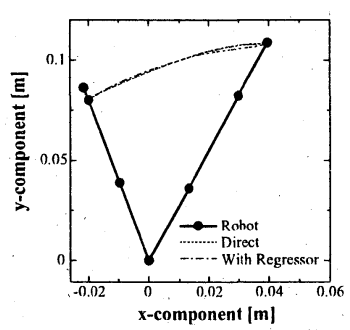

Fig. 16 Responses of $(x, y)$

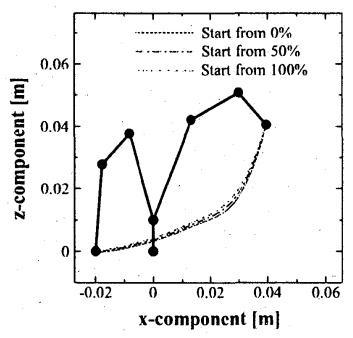

Fig. 18 Responses of $(x, z)$

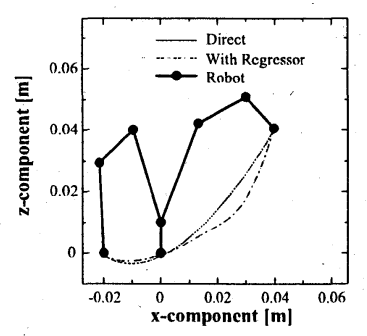

Fig. 17 Responses of $(x, z)$

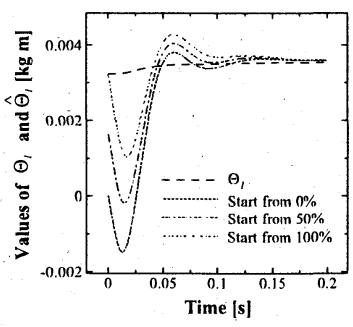

Fig. 19 Responses of $\hat{\Theta}_{1}$ and $\Theta$ $z=0$ の平面を突き破ってオーバーシュートし, $q_{2}+q_{3}+q_{4}$ は $-\pi / 2$ を通り越している. その結果, $Y$ のランク落ちが 起こり, 持続的励起 (persistently exciting) の条件が満た されなくなる．実用的には，真下から手前に引いた所でペン 書きすることはなく，また，指はペンの質量中心を支えるの が望ましいので, そのとき近似的に $s_{4}=0$ となり, 重力項 の第四成分 $g_{4}(q)$ は 0 に近く, 無視できるようになろう.

もし $s_{4}$ が無視できなければ, 回帰子 $Y$ を定数行列, 未 知パラメターをゆるやかに変動するべクトルとしてつぎの ように設定することもできる.

$$
Y=g\left(\begin{array}{ccc}
0 & 0 & 0 \\
1 & 1 & 1 \\
0 & 1 & 1 \\
0 & 0 & 1
\end{array}\right), \quad \Theta=\left(\begin{array}{c}
\theta_{1} \mathrm{c}_{2} \\
\theta_{2} \mathrm{c}_{23} \\
\theta_{3} \mathrm{c}_{234}
\end{array}\right)
$$

そして のの推定量を (10) 式と同様に

$$
\hat{\Theta}(t)=\hat{\Theta}(0)-\int_{0}^{t} \eta^{-1} Y^{\mathrm{T}} s(\tau) \mathrm{d} \tau
$$

と設定してみる.このとき, 同様にスカラ関数 $V$ が定義で きるが，その時間微分は (25) 式に対応して

$$
\begin{aligned}
\dot{V} \leq & -\frac{1}{2} \dot{q}^{\mathrm{T}} C \dot{q}-k^{2} \Delta \boldsymbol{x}^{\mathrm{T}} J C^{-1} J^{\mathrm{T}} \Delta \boldsymbol{x} \\
& -\beta \Delta \Theta^{\mathrm{T}} Y^{\mathrm{T}} C^{-1} Y \Delta \Theta-\eta \dot{\Theta}^{\mathrm{T}} \Delta \Theta
\end{aligned}
$$

となる. 最後の項が余計に現れるが,これは右辺の第一項 と第三項に余裕をもって繰り込めるので $\dot{V} は \dot{q}, \Delta x, \Delta \Theta$ に関して負定値となり，定理 1 が成立する。ここでは詳しい 議論は省くが，(35) 式と同じダンピング係数を与えたとき のシミュレーション結果を Fig. 18, 19 に示す. なお, 図 中の “Start from $50 \%$ ” は推定量の初期值 $\hat{\Theta}_{i}(0)$ を真值の $50 \%$ とし与えたときの結果を示し，ほかの $0 \%, 100 \%$ も 同様である.Fig. 18, 19 から，いずれの場合も $x y$ 平面を 
オーバーランすることなく目標点に収束するが, Fig. 6〜 10 などと比べて, 手先軌道は途中で少しぎくしゃくする.

\section{6.おわりに}

重力の影響下にある冗長関節ロボットについて, 3 次元 リーチング運動を考察し, 伝統的な方法とは異なるダンピ ング成形つき作業座標フィードバック制御法が十分な働きを することをシミュレーションで示し, 理論解析を行なった。 ロボティクス ${ }^{11)}$ や運動生理学 ${ }^{2), 12)}$ の多くの研究に見られ るような, 人為的な動作指標を導入し, その最小化によって 逆運動学の不良設定性を解消する方法とは異なり, この方法 は逆運動学や逆動力学を解く必要がない.しかし, 圥長自由 度系に特徴的に生起しうる "self-motion”がこの方法で完全 に回避できていることを一般的に証明するのは困難である. ここでは目標点への収束性とともに，持続的な self-motion がほほ起こり得ないことを理論的に示し, 全く起こり得てい ないことをシミュレーションで確かめた。

従来の手書きロボットの研究でも, 呪長自由度の解消のた めにさまざまなコスト関数が提案される一方 ${ }^{13), 14)}$, 生理学 の研究では午長性が未制御多様体仮説によって解消されて いるとの仮説も唱えられている ${ }^{14)}$. 本論文により, 前の論 文 ${ }^{4), 5)}$ と合わせて, 今までの漠然とした，あるいは人為的 な冗長性の解消法とは異なり, 単純かつ明解な方法でリー チングと手書き動作が実現できることが示されたことにな ろう.

最後に, ベルンシュタインが主張したように, 生体運動の 巧みさは文脈依存的であり, 一般的理論の構築は難しいと思 えるが, 本論文で提案した方法はほかのて長自由度系の制御 問題にも有効に機能すると考えている.

\section{参 考 文 献}

1） N.A.ベルンシュタイン (工藤, 佐々木 (訳) ):デクステリティ： 巧みさとその発達，金子書房 (2003)

2) M.L. Latash: Neurophysiological Basis of Movement, Human Kinetics Pub., Champaign, IL (1998)

3) S. Arimoto, M. Sekimoto, H. Hashiguchi and R. Ozawa: Natural resolution of ill-posedness of inverse kinematics for redundant robots: A challenge to Bernstein's degreesof-freedom problem, Advanced Robotics, 19-4, 401/434 (2005)

4) S. Arimoto, H. Hashiguchi and R. Ozawa: A simple control method coping with a kinematically ill-posed inverse problem of redundant robots:analysis in case of a handwriting robot, Asian J. of Control 7-2, 112/123 (2004)

5) H. Hashiguchi, S. Arimoto and R. Ozawa: Control of a handwriting robot with DOF redundancy based on feedback in task coordinates, J. of Robotics and Mechatronics, 16-4, 381/387 (2004)

6) H. Hashiguchi, S. Arimoto and R. Ozawa: A sensory feedback method for a handwriting robot with D.O.F. redundancy, Proc. of 2004 IEEE/RSJ Int. Conf. on Intelligent Robots and Systems, Sendai, Japan, 3918/3923 (2004)

7) S. Arimoto: Control Theory of Nonlinear Mechanical Systems: A Passivity-based and Circuit-theoretic Approach, Oxford Univ. Press, Oxford, UK (1996)
8) H. Seraji: Configuration control of redundant manipulators: Theory and Implementation, IEEE Trans. on Robotics and Automation, 5, 472/490 (1989)

9) S. Arimoto: Intelligent control of multi-fingered hands, Annual Review in Control, 28-1, 75/85 (2004)

10) S. Arimoto: A challenge to Bernstein's degrees-of-freedom problem in both cases of human and robotic multi-joint movements, Proc. of NOLTA 2004, Fukuoka, Japan, 1/14 (2004)

11) J. Lenarcic (ed.): Special Issue on Redundant Robots. Laboratory Robotics and Automation, 6-1 (1991)

12) N. Hogan: An organizing principle for a class of volundary movements, J. Newrosci., 4, 2745/2754 (1984)

13) V. Potkonjak, M. Popovic, M. Lazarevic and J. Sinanovic: Redundancy problem in writing: from human to authropomorphic robot arm, IEEE Trans. Systems, Man, and Cybernetics, 28-6, 790/805 (1998)

14) V. Potkonjak, S. Tzafestas, D. Kostic, G. Djoudjevic and M. Rasic: The handwriting problem, IEEE Robotics and Automation Magazine, March 2003, 35/46 (2003)

15) M.L. Latash: Approaches to analysis of handwriting as a task of corrdinating a redundant motor system, Human Movement Science, 22, 153/171 (2003)

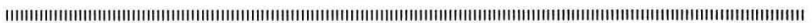

\section{[著 者 紹 介]}

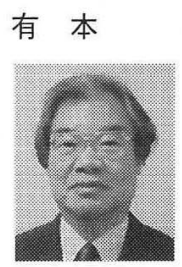

卓（正会員）

1936 年 8 月 3 日生. 59 年京都大学理学部数 学科卒業, 同年沖電気工業 (株), 62 年 2 月東 京大学工学部助手, 67 年講師を経て, 68 年大阪 大学基礎工学部助教授, 73 年 3 月同教授, 88 年 東京大学工学部教授, 97 年 3 月同停年退職, 同 年 4 月より立命館大学理工学部教授, 現在に至 る。この間, 制御理論, 情報理論, ロボティクス, マシーンインテリジェンスの研究に従事. 工学博 士. $95 \sim 97$ 年日本ロボット学会会長, 83 年 IEEE Fellow，2000 年 IEICE Fellow. 2000 年 IEEE Third Millennium Medal 受賞. 2000 年 4 月紫 綬裹章受章。

\section{橋口宏 衛 (学生会員)}

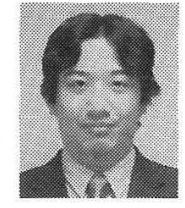

2001 年立命館大学理工学部ロボティクス学科 卒業. 2003 年立命館大学院理工学研究科情報シ ステム学専攻博士前期課程修了. 現在は立命館大 学院理工学研究科総合理工学専攻博士後期課程に 在籍、ロボットハンド，ロボットアームの力学と 制御に関する研究に興味を持つ. 日本ロボット学 会, IEEE 各会員 